\title{
A carreira dos profissionais do magistério do sistema municipal de educação de Belém (PA): o dito e o feito
}

\section{Teachers career in municipal education in Belém (PA): between the said and done}

\section{Dalva Valente Guimarães Gutierres ${ }^{1}$ \\ Rosana Maria Oliveira Gemaque ${ }^{2}$ Silvia Letícia D“Oliveira da Luz ${ }^{3}$}

\section{Resumo}

O presente artigo trata da análise da carreira do magistério público do município de Belém, na perspectiva de identificar indícios de valorização profissional no magistério. O objetivo é verificar se a carreira de professor na rede pública do município de Belém é efetiva e atrativa.. O artigo procura responder a essas questões por meio da análise documental e bibliográfica, especialmente do Estatuto do Magistério Municipal. Assim, buscou-se avaliar a efetividade da carreira docente evidenciando as conquistas previstas na legislação, as repercussões na remuneração dos professores e a valorização profissional. O estudo revelou que há uma profusão de leis que regimentam a carreira do magistério de Belém, dificultando aos professores a identificação de seus direitos; o estímulo ao exercício da docência; a atratividade, ainda que minimamente. O desafio na carreira reside na construção de condições objetivas para colocar em prática a progressão e a necessidade de sistematização de um Plano de Carreira, Cargos e Salários (PCCR) que considere a manutenção das conquistas atuais e o cumprimento das que persistem em existir apenas na letra da lei.

Palavras-Chave: Carreira do magistério;

Valorização do magistério; Magistério de Belém.

\begin{abstract}
This paper analyzes the teacher career at Belém municipality's public education system with the intention of identifying evidences of the valorization of this career. The objective is to verify if this career helps the initial admission into, the kind of professional who is attracted to it, if there is incentives to keep professors in classrooms, and if it promotes professional qualification, that is, if the career of professor at the public education system of Belém municipality is effective in attractiveness. This paper looks for answering those questions through documental and bibliographic analysis, mainly the analysis of the Estatuto do Magistério Municipal. It was also sought to evaluate the career's effectiveness through gains due to the law and its effects on professors' salaries and professional valorization. The study shows that there are: A profusion of laws regulating the teacher career in Belém, what brings difficulties to professors to indentify their rights; incentives to exercise the teaching activity; attractiveness, even though at a minimum level. The challenge lies in building objective conditions to put into practice the progression in systematization needs of a Career, Posts, and Salaries Plan (CPSP) that takes into account the sustaining of current achievements and the enforcement of those ones that exist only in the letter of the law.
\end{abstract}

Keywords: Teaching career, Teachership

Valorization, Belém's Teachership

1 Doutora em Educação. Professora da Universidade Federal do Pará. E-mail: dalvalen@ufpa.br

2 Doutora em Educação. Professora da Universidade Federal do Pará. E-mail: rgemaque@uol.com.br

3 Profissional da SEDUC e SEMEC/Belém-PA. E-mail: silvialeticialuz@yahoo.com.br 


\section{Introdução}

A cidade de Belém apresenta território de 1.059,4 Km², 1.392.031 habitantes, Produto Interno Bruto - PIB de 13.797.141(mil reais) e PIB per capita de 9.793 reais (IBGE, 2010). A Secretaria Municipal de Educação (SEMEC) ${ }^{4}$ coordena 59 escolas municipais, 53 unidades pedagógicas ou anexas e 34 Unidades de Educação Infantil (UEI), na qual atuam cerca de 2.400 professores e mais de 70.000 alunos (SEMEC, 2010).

A regulamentação das atividades funcionais dos professores tem sido fruto, sobretudo, da mobilização dos educadores que lutam pela construção de um Plano de Carreira, Cargos e Remuneração (PCCR). Na ausência desse instrumento, focalizaremos neste estudo o Estatuto do Magistério do Município de Belém $\mathrm{EMMB}^{5}$ e das leis correlatas.

Vários estudiosos ${ }^{6}$ têm se ocupado em definir o conceito de valorização do professor definindo diversos aspectos que podem contribuir à valorização do magistério, tais como: condições salariais dignas; formação inicial e formação continuada; Plano de Carreira; acesso à cultura; condições adequadas de trabalho (tempo para planejamento de aulas, acesso a bibliotecas, internet, equipamentos didáticos, número de alunos por turma), entre outros. Embora não haja divergência quanto à existência desses fatores para que haja valorização do profissional, alguns tendem a enfatizar um ou outro aspecto; todavia, todos são unânimes em um ponto: no reconhecimento de que a valorização do professor é de fundamental importância para a melhoria da educação.

A Lei de Diretrizes e Bases da Educação Nacional (Lei n 9.394/96) ressalta, no art. 67, a valorização dos profissionais da educação,

\footnotetext{
4 A organização da educação municipal em Belém data de 1949 com a criação da Diretoria de Ensino Municipal (Lei $n^{0} 503$ de 27/05), posteriormente transformado em Departamento Municipal de Educação e Cultura (Lei $n^{0} 4.107$, de 11/06/58) A SEMEC foi criada em 1968 (n. 6.658 de 04/06/68) (ROSÁRIO, 2008).

50 primeiro Estatuto do magistério municipal de Belém foi criado por meio da Lei $n^{\circ} 6.999$ de $27 / 07 / 76$, modificado pelas Leis $n^{0}$ 7.219 de $05 / 01 / 83$ e $n^{0} 7.281$ de $14 / 02 / 85$. Em 1987, por meio da Lei $\mathrm{n}^{0} 7.385$ de $07 / 12$ novo estatuto foi criado, sendo substituída pelo atual, Lei $n^{\circ} 7.528$, de 5/08/91.
}

6Dentre outros, destacam-se: Iria Brzezinski (2000), Ma Angela Aguiar (2000), Enguita (1991, 2004) Gatti (1996) Helena de Freitas (2002, 2007), Olgaíses Maués (2003) e Monlevade (2000). orientando para os estatutos e planos de carreira do magistério público; o ingresso exclusivamente por concurso público; o aperfeiçoamento profissional continuado, com direito à licença remunerada; o piso salarial profissional; a progressão funcional com base na titulação ou na habilitação com avaliação de desempenho; e as condições adequadas de trabalho.

A Confederação Nacional dos Trabalhadores em Educação - CNTE também defende que "carreira, piso salarial profissional, políticas de formação inicial e continuada são indispensáveis e determinantes na orientação e na consistência da qualidade da educação" (CNTE, 1997, p.15). Considerando os vários estudos existentes sobre o tema assume-se que a valorização dos profissionais da educação supõe formação inicial e continuada, salário digno, Plano de Carreira e condições adequadas de trabalho. Mas como essas diversas dimensões da valorização profissional, especialmente a carreira do magistério vem se materializando no município de Belém nas últimas décadas? A carreira fomenta o ingresso inicial e estimula a permanência em sala de aula? Promove a qualificação profissional? Por meio de análise documental e bibliográfica, procuramos responder estas questões.

O texto consta de três partes. Na primeira discute-se o processo e o contexto da organização da carreira do magistério no município de Belém; na segunda, são analisados os principais aspectos legais. E, na terceira, buscou-se demonstrar a efetividade no magistério.

\section{O contexto das mobilizações pela Carreira docente}

A organização da categoria docente no estado do Pará se insere em um conjunto de mobilizações locais e nacionais que ocorreram desde o final da década de 1970, tais como as greves do ABC paulista e, posteriormente o movimento pelas "Diretas Já", em meados da década de 1980.

Um marco na organização dos professores ocorreu em 1979, na "marcha pela educação" ocasião em que, conjuntamente aos movimentos de bairros reivindicavam-se o direito à educação, a salários dignos e à regulamentação da profissão. 
Neste contexto, a organização docente reivindicava seus direitos e fundava a Associação dos professores do Estado do Pará (APEPA), coordenada por professores e militantes que organizavam as Comissões de Bairros de Belém e associações em municípios do Estado, principalmente os do Baixo Tocantins. Em 1983 esta entidade transformou-se em Federação dos Professores Públicos do Estado do Pará (FEPPEP) e após a Constituição de 1988, Sindicato dos Trabalhadores em Educação Pública do Pará (SINTEPP).

Nesta época, em 1983, houve uma greve contra o então governador Jáder Barbalho na qual se conquistou o salário mínimo para os professores primários e a readmissão de todos os que haviam sido demitidos pela ditadura militar. Essa greve unificou e marcou a história da categoria.

Por toda a década de 1980 houve mobilizações dos professores, nas quais perpassaram vários governos pela Prefeitura Municipal de Belém $(\mathrm{PMB})^{7}$, especialmente após a ditadura militar. Os prefeitos nomeados ou eleitos e que em diferentes momentos dialogaram ou reprimiram o movimento sindical em Belém são apresentados a seguir:

\section{Quadro 01: Prefeitos de Belém nomeados e} eleitos de 1980 a 2010

\begin{tabular}{|c|c|c|c|}
\hline Nome & Partido & Período & Situação \\
\hline Loriwal Rei de Magalhães & Arena & 1980 a 1983 & Nomeado \\
\hline Sahid Xerfan & PMDB & 1983 (04-08) & Nomeado \\
\hline Almir José de Oliveira Gabriel & PMDB & 1983 a 1986 & Nomeado \\
\hline Fernando Coutinho Jorge & PMDB & 1986 a 1989 & Eleito \\
\hline Sahid Xerfan & PTB & 1989 a 1990 & Eleito \\
\hline Augusto Resende & PTB & 1990 a 1992 & Eleito \\
\hline Helio Gueiros & PFL & 1993 a 1996 & Eleito \\
\hline Edmilson Rodrigues & PT & 1997 a 2004 & Eleito \\
\hline Duciomar Costa & PTB & 2005 a 2012 & Eleito \\
\hline
\end{tabular}

Fonte: Imprensa paraense

Em 1987, os professores da rede municipal de ensino de Belém entraram em greve acompanhando os professores estaduais na qual os dirigentes do

7 Até 1986 os prefeitos municipais de Belém eram nomeados pelo governador do Estado, acompanhando a conjuntura nacional do regime autoritário iniciado em 1964.
SINTEPP, fizeram greve de fome como medida para pressionar o governo a recebê-los. À época, o governador Hélio Gueiros havia demitido 90 diretores de escolas grevistas, suspendendo o pagamento dos professores dessas escolas.

No governo de Augusto Rezende foi possível conquistas importantes na carreira do magistério de Belém, assegurados no atual Estatuto do Magistério. Em 1996, o Professor Edmilson Rodrigues (ex-dirigente do SINTEPP) foi eleito Prefeito de Belém pelos partidos da Frente Popular liderados pelo PT. Na época, a categoria se mobilizou em prol da reformulação do Estatuto do Magistério de Belém que foi construída em parceria prefeiturasindicato e a categoria, mas que não foi efetivada. No início desse governo, houve o enquadramento na carreira de cerca de $3 \%$ da categoria dos professores - os que ingressaram na década de 1970 -, em relação à progressão horizontal, não sendo possível aos demais por restrições orçamentárias, segundo argumento do governo. A carreira ficou paralisada, o que motivou ocasionando fortes greves no referido mandato.

Em 2005, o prefeito Duciomar Costa, do PTB assumiu a PMB com a proposta de implantar um Plano de Cargos dos servidores da administração direta, o que reordenaria regulamentações na carreira docente expressas no Estatuto do Magistério, mas que não foi implementado até o momento.

\section{As possibilidades da carreira do Magistério Público de Belém na Legislação: o dito}

A forma de provimento dos cargos efetivos que compõem o magistério público do município de Belém depende de prévia aprovação em concurso público, de provas e de títulos. A nomeação ocorre por decreto do prefeito, considerando a ordem de classificação (Lei n 7.528 de 05/08/91 - EMMB), o que já existia desde os primeiros estatutos, antes da Constituição Federal de 1988. No entanto, ainda se mantém a prática de contratos temporários para professores, como política permanente dos governos municipais fomentada pela ausência de concursos públicos periódicos ${ }^{8}$.

80 último concurso público realizado na Prefeitura Municipal de Belém para professores ocorreu em 2000, ou seja, há 10 anos. 
Até 1991, a Lei nº 7.385 de 07/12/87 (Dispunha sobre o EMMB) estabelecia que o Grupo do Magistério compreendesse as categorias de Docentes e Especialistas em Educação. O atual estatuto (Lei n 7.528 de 05/08/91 - EMMB) unificou estas categorias por considerar que as funções de Administrador Escolar, Orientador Educacional, Supervisor Educacional fazem parte das atividades do Magistério.

A estrutura básica de Cargos de provimento efetivo do Magistério de Belém constitui-se das seguintes categorias funcionais e formações mínimas:

\section{Quadro 02: Categoria Funcional do Magistério Público da Rede municipal de Belém}

\begin{tabular}{|c|c|c|}
\hline Categoria Funcional & Código & Formação \\
\hline Supervisor Escolar & MAG 7 & Pedagogia \\
\hline Orientador Educacional & MAG 6 & Pedagogia \\
\hline Administrador Escolar & MAG 5 & Pedagogia \\
\hline Professor Licenciado Pleno & MAG 4 & Licenciatura Plena \\
\hline $\begin{array}{c}\text { Professor em Estudos } \\
\text { Adicionais }\end{array}$ & MAG 2 & $\begin{array}{c}\text { Magistério e } \\
\text { Estudos Adicionais }\end{array}$ \\
\hline $\begin{array}{c}\text { Professor Pedagógico } \\
\text { MAG 1 }\end{array}$ & $\begin{array}{c}\text { Médio - } \\
\text { Magistério }\end{array}$ \\
\hline
\end{tabular}

Fonte: Lei $n^{\circ} 7.528$, de 5 de agosto de 1991.

A função de administrador escolar não coincide necessariamente com a de diretor, visto que o administrador é admitido por concurso e o diretor é escolhido mediante processo seletivo e eleição.

A jornada de trabalho do magistério poderá ser de 20, 30, ou 48 horas/aulas por semana para - Supervisor Escolar, o Orientador Educacional, - Administrador Escolar e o Professor, com exercício em Unidades Escolares ou nos níveis departamentais da SEMEC (Art. 25 da Lei no 7.528 de 05/08/91- EMPMB). A definição do quantitativo de carga horária depende da necessidade de serviço, sendo fixada por ato expresso do titular da SEMEC. No entanto, os especialistas, geralmente, assumem 150 horas de jornada mensal.

A jornada de trabalho do Professor é constituída de atividades docentes em sala de aula e atividades fora de classe (Art. 26 do EMPMB), a título de hora-atividade, correspondendo a $20 \%$ da carga horária total. Uma parte é cumprida nas escolas como Hora Pedagógica (HP), ocasião em que os professores se reúnem para planejamento e troca de experiências e outra é utilizada para correção e planejamento de trabalhos dos alunos. Há, portanto, possibilidade dos professores assumirem jornadas de 100, 150, 200 horas mensais de trabalho, o que é definido pela SEMEC.

Segundo o estatuto, a promoção do funcionário municipal do Grupo de Magistério é feita por Progressão Funcional Horizontal e Vertical.

A progressão funcional vertical seria a passagem do professor efetivo para outra categoria funcional de professor, ao adquirir qualificação em outro nível, bastando para isso apresentação de documentação comprobatória de escolaridade junto à SEMEC ${ }^{9}$. O funcionário seria, então, enquadrado na referência inicial da nova categoria, a qual teria direito após a progressão. A progressão prevista não permite a ascensão da categoria de professores para especialistas ou vice-versa (Art.4 $4^{\circ} \S 1^{\circ}$ da Lei 7.673 de 21/12/93).

A progressão horizontal seria feita a partir de dois critérios: o primeiro, por antiguidade a cada interstício de 2 anos; o segundo, por merecimento, mediante avaliação de desempenho, a cada interstício de 4 anos. A progressão por antiguidade supõe 13 referências e 5\% de adicional salarial a cada uma $^{10}$. Considerando que as professoras aposentam-se aos 25 anos de contribuição, dificilmente alcançarão a amplitude total da carreira, prevista em 26 anos, pelas 13 referências da carreira.

Os adicionais, as gratificações e os auxílios são vantagens pecuniárias concedidas aos servidores em caráter definitivo ou transitório, em razão do tempo de serviço, pelo desempenho de funções especiais, em razão das condições anormais em que se realiza o serviço ou, finalmente, por condições pessoais do servidor. O adicional se refere a "uma recompensa pelo tempo de serviço do servidor ou uma retribuição pelo desempenho de funções especiais" (JÚNIOR et all, s/d, p. 93), enquanto que "a gratificação é uma compensação por serviços comuns executados em condições

9 Art. $4^{0} \S 2^{0}$ da Lei 7.673 de 21/12/93 - Dispõe sobre 0 sistema de promoção do Grupo Magistério.

10 Art. 11 da Lei 7.528 de 05/08/91 - Dispõe sobre o EMPMB. 
anormais para o servidor ou uma ajuda pessoal em face de certas situações que agravam o orçamento do servidor" (JúNIOR et all, s/d, p. 93). Por conseguinte, o adicional está relacionado ao tempo e à função e tem caráter permanente, podendo inclusive incorporar-se aos vencimentos. As gratificações se relacionam com o serviço que está sendo executado ou com a condição dos servidores em um determinado momento e, por isso, tem caráter contingencial ou transitório.

O Estatuto dos Funcionários Públicos do Município de Belém - EFPMB (Lei 7.502 de 20/12/90) prevê os seguintes adicionais que se aplicam aos professores: I - por tempo de serviço; II - de férias (1/3 sobre a remuneração); III - de escolaridade e V - de cargo em comissão. $\mathrm{O}$ adicional por tempo de serviço (Art.80, § $1^{\circ}$ ), prevê 5\% por triênio de exercício até o máximo de 12, conforme o quadro a seguir:

Quadro 03: Percentuais dos Adicionais por tempo de serviço

\begin{tabular}{|c|c|c|}
\hline Incisos & Tempo em anos & Valor Percentual \\
\hline I & 3 & $5 \%$ \\
\hline II & 6 & $10 \%$ \\
\hline III & 9 & $15 \%$ \\
\hline IV & 12 & $20 \%$ \\
\hline V & 15 & $25 \%$ \\
\hline VI & 18 & $30 \%$ \\
\hline VII & 21 & $35 \%$ \\
\hline VIII & 24 & $40 \%$ \\
\hline IX & 27 & $45 \%$ \\
\hline X & 30 & $50 \%$ \\
\hline XI & 33 & $55 \%$ \\
\hline XII & Após 34 anos & $60 \%$ \\
\hline
\end{tabular}

Fonte: Lei 7.502 de 20 de dezembro de 1990

O adicional de escolaridade é calculado sobre o vencimento-base nas seguintes proporções: $20 \%$ aos funcionários portadores de certificado do $1^{\circ}$ Grau (ensino fundamental); $60 \%$ aos funcionários que concluíram o $2^{\circ}$ Grau (ensino médio); e $100 \%$ aos que concluíram o Ensino Superior (art. 83 da Lei 7.502 de 20/12/90) ${ }^{11}$.

110 art.43 do Estatuto do magistério de 1991 assegura a validade do art. 87 do Estatuto do Funcionário Público municipal de 1990 em relação aos adicionais para os professores.
O Estatuto do Magistério também prevê a concessão das seguintes vantagens pecuniárias (art. 37 da Lei $n^{\circ} 7.528$ de 05/08/91):

A. Gratificação de 20\% por regência de classe sobre o respectivo vencimento-base;

B. Gratificação de Magistério, correspondente a 10\% do vencimento-base (após 25 anos de efetivo exercício).

C. Incentivo ao aperfeiçoamento, na forma da lei.

O atual Estatuto do magistério (1991) definiu a necessidade de gratificações de incentivo ao aperfeiçoamento (Art. 37, VI), remetendo a matéria à regulamentação específica, aprovada pela Lei n 8.487 em 29 de/12/2005. De acordo com o Art. $2^{\circ}$ desta Lei, as gratificações de incentivo ao aperfeiçoamento são calculadas sobre o vencimento do professor nos seguintes percentuais: $35 \%$ para doutorado; 30\% para mestrado; 25\% para especialização com carga horária igual ou superior a 360 horas; 40\% para os ocupantes de cargo de nível médio possuidores de diploma de curso de graduação; 7,5\% para curso de aperfeiçoamento com carga horária igual ou superior a 180hs. As gratificações, contudo, não são cumulativas, exceto a referente aos $40 \%$ de nível superior.

Os profissionais do magistério também fazem jus à gratificação natalina (correspondente a um doze avos da remuneração por mês de exercício no respectivo ano civil) a ser paga em dezembro em forma de $13^{\circ}$ salário (art. 75 da Lei n 7.502 de 20/12/90 - EFPMB) e seus vencimentos mensais não poderão ser inferiores ao salário mínimo legal (Art. 52 da Lei n 7.502 de 20/12/90 - EFPMB).

O funcionário público do município de Belém, dentre os quais se inclui o professor, recebe saláriofamília correspondente a 5\% do vencimento-base por dependente (Art. 170 da Lei n 7.502 de 20/12/90 - EFPMB). São considerados dependentes: filhos até 18 anos; inválidos de qualquer idade (neste caso o percentual do salário família é de $10 \%$ do salário mínimo); filhos estudantes até 24 anos que não possuam renda própria, enteado e tutelado. Além disso, a Lei Orgânica municipal prevê aos funcionários públicos de Belém auxílio-creche, vale-transporte e vale-refeição (Art. 18).

Outros auxílios assegurados pelo Estatuto dos Funcionários municipais (Lei n 7.502 de 
20/12/90) são: auxílio-natalidade, auxílio-funeral e auxílio-reclusão.

O auxílio-natalidade é devido à funcionária por motivo de nascimento de filho, em quantia equivalente a duas vezes ao menor vencimento básico pago pelo Município, inclusive no caso de natimorto. Esse auxílio se estende a cônjuge ou companheira do funcionário municipal. Em havendo a morte do funcionário antes de acontecido o parto, a viúva ou companheira terá direito ao recebimento do auxílio-natalidade. Na hipótese de parto múltiplo, o valor pago é proporcional ao número de filhos.

O auxílio-funeral é devido à família do funcionário falecido na atividade ou do aposentado, em valor equivalente a duas vezes o menor vencimento básico pago pelo Município.

O auxílio-reclusão é devido à família do funcionário afastado do cargo por motivo de prisão ou condenado judicialmente à pena que implique em perda do cargo, no valor correspondente a setenta e cinco por cento (75\%) da remuneração, que cessará a partir do dia imediato àquele em que o funcionário for posto em liberdade, mesmo que condicional.

Para os professores há, ainda, a previsão de gratificações por participação em bancas examinadoras em concursos do Magistério, bem como a concessão de prêmio pela produção de obra e publicação de trabalho de interesse da educação e da cultura (Art. 37, inciso II e III da Lei 7.528, de 05/08/91 - EMMB). No entanto, não há especificação de percentuais de gratificação ou a que tipo de prêmio o legislador se refere.

Os profissionais do Magistério têm direito a 45 dias de férias (Art.27 a 29 da Lei no 7.528/91 - EMMB), fazendo jus ao adicional de $1 / 3$ da remuneração correspondente ao período de férias.

Quanto às licenças, os profissionais do magistério de Belém têm direito a algumas, como funcionários públicos: I - para tratamento de saúde; II - por motivo de acidente em serviço; III - por motivo de doença em pessoa da família; IV - à gestante; V - paternidade; VI - por motivo de afastamento do cônjuge; VII - para prestação de serviço militar; VIII - para atividade política; IX - para atividade sindical; $X$ - a título de prêmio por assiduidade e comportamento; $\mathrm{XI}$ - para tratar de interesse particular (Art. 93 da Lei no 7.502 de 20/12/90 - EFPMB).
As licenças não poderão ultrapassar dois anos, salvo nos casos de afastamento do cônjuge, prestação de serviço militar, atividade política e para atividade sindical.

A licença por motivo de doença em pessoa da família só poderá ser concedida caso se verifique que a assistência direta do funcionário é indispensável e que não pode ser prestada simultaneamente ao exercício do cargo. Caso ocorra, será com vencimentos integrais até 90 dias; se por mais de 120 dias ou até um ano, o funcionário recebe 1/3 do seu salário e após um ano perde o direito ao salário.

A licença para acompanhamento de cônjuge para outro ponto do território nacional será concedida por prazo indeterminado, mas sem remuneração (Art. $107 \S 1^{\circ}$ da Lei $n^{\circ} 7.502$ de 20/12/90 - EFPMB).

A licença como prêmio de assiduidade e comportamento é de 60 dias a cada período de 3 anos de exercício, caso o funcionário não tenha sofrido penalidade disciplinar ou criminal, não tenha se afastado do cargo por outro tipo de licença nem tiver falta injustificada por mais de 6 dias (Art. 112, da Lei $n^{\circ} 7.502$ de 20/12/90 - EFPMB).

Ao professor também são concedidas licenças para frequentar cursos de aperfeiçoamento ou especialização e para participar de congressos, simpósios ou promoções similares, no país e no exterior, de natureza profissional ou sindical. (Art. 35, inciso II da Lei n 7.528, de 05/08/91 EMMB). Nos casos de licença para capacitação com ônus para o Município, o professor é obrigado a permanecer na instituição por período equivalente ao do curso realizado, sob pena de ressarcimento das despesas efetuadas.

A ausência ao trabalho por motivo injustificado motivou a adoção de política de desconto de faltas regulamentada na lei $n^{\circ}$ Lei $n^{\circ} 7.638$ de 24/05/93 que disciplina o desconto com base na remuneração total.

De acordo com o Estatuto do Magistério os cargos de Diretor e Vice-Diretor das escolas são considerados cargos em comissão, sendo exercidos por profissionais do Magistério habilitados em Administração Escolar e experiência mínima de 2 anos no Magistério (art. $7^{\circ}$ da Lei 7.528, de 05/08/91 - EMMB). No entanto, em 1994, a Lei $n^{\circ}$ 
7.722/94 que criou o sistema municipal de educação definiu que qualquer docente poderia ser candidato ao cargo de diretor (art. 16, 17,18). Em 1996 por meio da Portaria $n^{\circ} 762$, de 10/06/96 a SEMEC definiu que somente professores com habilitação em Administração Escolar poderiam se candidatar ao cargo, cujo processo de escolha implicava em análise de projeto pedagógico próprio, da vida funcional, entrevista e posterior eleição.

Por ocasião do governo da Frente Popular (1997-2004) e sob os auspícios da Escola Cabana realizou-se, em 1998, a I Conferência Municipal de Educação que deliberou pela eleição direta para diretor escolar e pela candidatura de qualquer professor licenciado pleno do quadro efetivo. Por meio da Resolução no 010/2001, o Conselho Municipal regulamentou tal processo de escolha, que prevaleceu até 2004, quando assumiu o governo Duciomar Costa (PTB), retomando a escolha de diretor conforme se fazia em 1996.

Como cargo comissionado o diretor escolar, faz jus à gratificação de 50\% sobre o seu salário a título de tempo integral e de 100\% por dedicação exclusiva, sendo não cumulativas (Art. 64 da Lei $n^{\circ}$ 7.502/20/12/90 - EFPMB). Cessado o exercício, fará jus ao adicional correspondente à quinta parte da diferença entre o vencimento do cargo efetivo $e$ o vencimento do cargo em comissão, por ano de efetivo exercício, até o máximo de cinco quintos (Art. 86 e 87 da Lei no 7.502 de 20/12/90 - EFPMB).

\section{A efetividade da Carreira do Magistério no município de Belém: o feito}

Ao cotejar as premissas da lei com a realidade dos profissionais da educação verifica-se que ainda que os governos coloquem como meta a valorização profissional em seus programas, nem sempre isso é materializado. No governo da Frente Popular (1997 a 2004) ${ }^{12}$, por exemplo, o programa trazia as seguintes metas:

- Implantar piso salarial profissional municipal resultante de ampla negociação entre Governo Popular e as entidades de classe;

- Construir um Fundo de Valorização dos Profissionais da Educação, composto por recursos previstos na

120 Governo da Frente Popular (PT) foi o mais progressista que Belém já vivenciou e gerou muitas expectativas pela proposta avançada de Educação denominada de Escola Cabana. Governou de 1997 a 2000, sendo reeleito para 2001 a 2004.
Constituição e orçamentados com base no princípio da prioridade da educação; verbas advindas de fontes internacionais e contribuições de entidades estatais, públicas ou privadas comprometidas com a educação pública de qualidade. 0 fundo será administrado pelo Fórum de Educação do Município de Belém;

- Garantir o cumprimento do Estatuto do Magistério e iniciar sua reformulação para adequá-lo a novas demandas dos profissionais de Educação;

- Incentivar à Habilitação em todos os níveis que implique em progressão vertical;

- Garantir a Formação continuada para todos os trabalhadores da Educação como instrumento que contribua para a reflexão e a transformação da prática educativa. Será assegurada em serviço e deve partir das experiências vivenciadas por estes, para a construção da educação pública de qualidade;

- Criação do Fundo de Valorização dos Trabalhadores em Educação.

(FRENTE BELÉM POPULAR, 1996, p. 24, apud Luz 2008).

A maior parte das metas não foi materializada, principalmente as que diziam respeito às progressões (vertical e horizontal) e as relativas à ascensão funcional, que nunca lograram êxito. Estas e outras questões são constantes nas pautas de negociação do SINTEPP junto à prefeitura, como se pode constatar em uma delas divulgada por ocasião da greve de 54 dias realizada no início de 2002, por meio da qual se pleiteava:

1. Resíduo Salarial de 1991 e 1992 igual a 65\%: do pagamento imediato para todos os servidores; Reposição salarial da inflação de maio/2001 a abril/2002;

2. Reposição das perdas do Plano Real para professores e funcionários;

3.Progressão Horizontal e Vertical com enquadramento imediato na carreira do magistério;

4. Recesso Escolar Remunerado para os funcionários de apoio e administrativo;

5. Vale-transporte entregue conjuntamente ao contracheque, cumprimento do acordo de 2001;

6. Pagamento de insalubridade para merendeiras e serventes;

7. Lotação: nenhum corte de carga horária em função do novo desenho curricular;

8. Formação Inicial Superior através de convênios com a UEPA e UFPA; 
9. Enquadramento das monitoras que terminaram 0

Ensino Normal, cumprindo a Lei 7.973.

(SINTEPP, 2002, apud LUZ, 2008, p. 109).

A pauta de reivindicações é por si só reveladora do descumprimento do estatuto do magistério e das pautas de compromisso do governo. Importa destacar que ao final da greve de 2002 houve alguns ganhos, que foram enumerados pela própria SEMEC, em publicação após a negociação com os professores:

1 - Garantia de 9,53\% para parte da categoria, que corresponde à perda inflacionária; 2 - Progressão em uma referência na carreira para os da década de 70; 3 - política de abono salarial; 4 - pagamento de vale-transporte contíguamente ao contra-cheque; 5 formação continuada no programa da SEMEC com certificação de carga-horária; 6 - enquadramento das monitoras na categoria do magistério $01 \mathrm{em}$ duas etapas; 7-... 8 - rediscussão do funcionamento do IPAMB [Instituto Previdência e Assistência do Município de Belém]; 9 - garantia de incentivo a estudos adicionais: especialização, mestrado e doutorado, com liberação de jornada de trabalho para estudos; 10 - retomada imediata da comissão Paritária (governo e sindicato) para que melhore quanto ao Estatuto do Magistério, questão da Insalubridade, (BELÉM. SEMEC, 2002, p. 2 apud LUZ, 2008, p. 111).

Um dos ganhos significativos por meio da greve de 2002 foram o enquadramento dos monitores da educação infantil na carreira do magistério e a obtenção de incentivos para estudos de pós-graduação (especialização, mestrado e doutorado), bem como liberação para estudo. Outros não foram cumpridos, o que ocasionou nova greve em 2004, cuja pauta de reivindicações pouco diferia da anterior (2002) com o SINTEPP que insistia nos mesmos temas:

1. Pagamento de Progressão Horizontal com aumento real de salários;

\section{Progressão Vertical;}

3. Pagamento de perdas históricas;

4. Incorporação do Abono nos vencimentos;

5. Vale transporte para prestadores de serviço;

6. Recesso escolar remunerado para todos os funcionários;

7.Pós-graduação e graduação para todos os trabalhadores em educação, com o intuito de melhorar a formação dos docentes e funcionários;
8. Pagamento de insalubridade;

9. Reformulação do Estatuto do Magistério;

10. Criação do cargo de coordenadores (as) das UEls por decreto;

11. Incorporação de hora-pedagógica aos vencimentos dos docentes;

12. Vale transporte para os efetivos, sem cobrança dos $6 \%$;

(SINTEPP, 2004, p. 1, apud LUZ, 2008).

A reformulação do Estatuto do Magistério, até o final de 2010 não foi atendida. Mas como essa legislação repercute na remuneração dos professores? Os dados da tabela 1 revelam a evolução dos ganhos de 1996 a 2010 para os professores em início de carreira com jornadas de 20, 30 e 40 horas, atualizados com base no Índice Geral de Preços-Disponibilidade Interna - IGP-DI/FVG ${ }^{13}$ de maio de 2010, como se pode acompanhar na tabela a seguir:

Tabela 1: Evolução do Vencimento Base* dos Professores do Município de Belém (Início da Carreira)

\begin{tabular}{|c|c|c|c|c|c|c|}
\hline & 1996 & 2000 & 2005 & 2010 & $\%$ cres. \\
\hline \multirow{3}{*}{$\begin{array}{l}\text { D) } \\
\text { D } \\
\text { In }\end{array}$} & EM & 394,21 & 422,83 & 450,17 & 619,28 & 57,10 \\
\hline & LP & 587,60 & 633,54 & 534,93 & 722,50 & 22,96 \\
\hline & ESP & 587,60 & 633,54 & 534,93 & 587,60 & 22,96 \\
\hline \multirow{3}{*}{ 永 } & EM & - & - & - & - & - \\
\hline & LP & 797,45 & 859,78 & 725,97 & 980,53 & 22,96 \\
\hline & ESP & 797,45 & 859,78 & 725,97 & 980,53 & 22,96 \\
\hline \multirow{3}{*}{$\begin{array}{l}\text { ㄲo } \\
\text { o }\end{array}$} & EM & 788,41 & 845,66 & 900,34 & $1.238,57$ & 57,10 \\
\hline & LP & $1.007,33$ & $1.085,92$ & 917,02 & $1.238,57$ & 22,96 \\
\hline & ESP & $1.007,33$ & $1.085,92$ & 917,02 & $1.238,57$ & 22,96 \\
\hline
\end{tabular}

Fonte: Diário Oficial e Decretos. Corrigido pelo IGPD-I a preço de maio/2010. ( $\left.{ }^{*}\right)$ A hora atividade é agregada ao vencimento base.

A evolução salarial de 1996 a 2010 foi de $57.1 \%$ para professores com formação em nível médio e de 22,96\% para os de formação em nível superior e especialização, independentemente de carga horária, o que revelava maior atenção às questões salariais dos professores com formação em nível médio.

130 IGP-DI/FGV foi instituído em 1944 com a finalidade de medir 0 comportamento de preços em geral da economia brasileira. 
Mas qual a é composição do salário docente? Quais são os percentuais de gratificação que o compõem? As informações da tabela 2 respondem a esses questionamentos:

Tabela 2: Participação Percentual do Vencimento Base ê Gratificacões na Remuneração dos Professores do Município de Belém - Formação Nível Médio (Início da Carreira)

\begin{tabular}{|c|c|c|c|c|c|c|}
\hline & & 1996 & 2000 & 2005 & 2010 & $\%$ cres. \\
\hline & REM & 709,57 & 761,09 & 810,31 & $1.114,71$ & 57,1 \\
\hline I & $\%$ VENC & 55,56 & 55,56 & 55,56 & 55,56 & \\
\hline & $\%$ GRAT & 44,44 & 44,44 & 44,44 & 44,44 & \\
\hline & REM & $1.419,14$ & $1.522,19$ & $1.620,61$ & $2.229,42$ & 57,1 \\
\hline 몽 & $\%$ VENC & 55,56 & 55,56 & 55,56 & 55,56 & \\
\hline & $\%$ GRAT & 44,44 & 44,44 & 44,44 & 44,44 & \\
\hline
\end{tabular}

Fonte: Diário Oficial. Corrigido pelo IGP-DI a preço de maio/2010.

$\left.{ }^{*}{ }^{*}\right)$ Não há professor de nível médio lotado com 150 hs.

A composição salarial dos professores municipais com formação em nível médio é constituída $55,56 \%$ de vencimento base e $44,44 \%$ de gratificações, de 1996 e 2010. Isto pode significar perda de aproximadamente a metade do salário após aposentadoria, caso não sejam incorporadas.

Se considerarmos que a Lei $\mathrm{n}^{\circ} 11.739$ de 16/07/2008 definia piso salarial de $R \$ 950,00$ para professores com nível médio e jornada de 40 horas em 2008, o sistema municipal apresenta valores acima dos previstos como piso, já que naquele ano o valor do vencimento básico do professor nessa condição equivalia a $\mathrm{R} \$ 1.115,00$ (valor nominal).

Quanto aos professores com formação em nível superior e diferentes jornadas em início de carreira, a tabela $n^{\circ} 3$ traz as seguintes informações:
Tabela 3: Participação Percentual do Vencimento Base e Gratificações na Remuneração dos Professores do Município de Belém - Formação Nível Superior (Início da Carreira)

\begin{tabular}{|c|c|c|c|c|c|c|}
\hline & & 1996 & 2000 & 2005 & 2010 & $\%$ \\
\hline & REM & $1.292,71$ & $1.393,80$ & $1.371,59$ & $1.589,49$ & 22,96 \\
\hline II & $\%$ VENC & 45,45 & 45,45 & 45,45 & 45,45 & \\
\hline & $\%$ GRAT & 54,55 & 54,55 & 54,55 & 54,55 & \\
\hline & REM & $1.754,38$ & $1.893,02$ & $1.863,14$ & $2.157,17$ & 22,96 \\
\hline 仿 & $\%$ VENC & 35,29 & 35,29 & 35,29 & 35,29 & \\
\hline & $\%$ GRAT & 64,71 & 64,71 & 64,71 & 64,71 & \\
\hline & REM & $2.216,13$ & $2.216,13$ & $2.389,21$ & $2.724,84$ & 22,96 \\
\hline 诖 & $\%$ VENC & 45,45 & 45,45 & 45,45 & 45,45 & \\
\hline & $\%$ GRAT & 54,55 & 54,55 & 54,55 & 54,55 & \\
\hline
\end{tabular}

Fonte: Tabelas Salariais - Diário Oficial e Decretos. Corrigido pelo IGP-DI a preço de maio/2010.

A remuneração dos professores com formação em nível superior com jornada de 20 e de 40 horas semanais revela composição idêntica: $45,45 \%$ de vencimento básico e de $54,55 \%$ de gratificações. Maior discrepância ocorre, ainda, com o salário dos professores que assumem jornada de 30 horas, os quais contam com apenas $35,29 \%$ de vencimento-base contra $64,71 \%$ de gratificações.

Quanto aos professores que possuem pós-graduação em nível de especialização, a composição salarial dos que possuem 20 horas semanais é semelhante à dos que possuem nível superior: $45,45 \%$ de vencimento-base e $54,55 \%$ de gratificações. Não obstante, para os de jornada de 30 e de 40 horas semanais $57,45 \%$ da remuneração corresponde a gratificações, o que pode estar associado à Lei de incentivo ao aperfeiçoamento. 


\section{Considerações Finais}

Retomando as perguntas que norteiam o presente artigo verificamos que no plano legislativo, a carreira do magistério é bastante avançada, porém muito dispersa, com informações em diversos documentos, tais como: Lei Orgânica Municipal, Estatuto do Funcionário Público do Município de Belém - EFPMB; Plano de Carreira do Quadro de Pessoal da Prefeitura Municipal de Belém - PCQPPMB; Estatuto do Magistério do Município de Belém - EMMB; Lei 7.673 de 21/12/1993 - Dispõe sobre o sistema de promoção do Grupo Magistério, modificada pela Lei $n^{\circ} 7.853$ de 24/11/1997; Lei no 7.638 de 24 de maio de 1993 - Disciplina o desconto por motivo de falta de integrantes da Carreira do magistério; Lei no 8.487 de 29/12/2005 - Dispõe sobre a concessão de incentivo ao aperfeiçoamento.

Essa profusão de leis tende a dificultar aos professores a identificação de seus direitos. Entretanto, algumas conquistas nesse processo de luta são bastante significativas no sentido da valorização profissional, tais como: a possibilidade de capacitação em nível de pós- graduação (Mestrado ou Doutorado), com licença remunerada para este fim e a manutenção das gratificações aos que permanecem em sala de aula, o que funciona como estímulo para o exercício da docência; concurso público; gratificações de escolaridade e possibilidades de progressão horizontal e vertical. O vencimento base também ficou acima do piso salarial propugnado em lei nacional em 2008, o que demonstra o esforço de manter o mínimo indispensável para a atratividade da carreira. Não obstante, a maior parte da composição salarial dos professores com nível superior e com especialização é feita de gratificações, o que denota dificuldades de se manter a remuneração após a aposentadoria, já que as gratificações são transitórias e passíveis de corte. O desafio de se conseguir condições objetivas de se colocar em prática a progressão na carreira aponta para a necessidade de se continuar a luta pela sistematização do Plano de Carreira, Cargos e Remuneração (PCCR) que considere a manutenção das conquistas atuais e o cumprimento daquelas que teimam em existir apenas na letra da lei.

\section{Referências Bibliográficas}

AGUIAR, M.A. Institutos superiores da educação na nova LDB. In: BRZEZINSKI, I (Org.). LDB interpretada: diversos olhares se entrecruzam. $4^{a}$ ed. SP: Cortez, 2000.

BRZEZINSKI, I. A formação e a carreira de profissionais da educação na LDB 9.394/96: possibilidades e perplexidades. In: BRZEZINSKI, I (Org.). LDB interpretada: diversos olhares se entrecruzam. 4ª ed. SP: Cortez, 2000.

CNTE - Confederação Nacional dos Trabalhadores em Educação - Cadernos de Educação. $1^{a}$ Ed. Ano Il, n 6. Agosto de 1997.

ENGUITA, M. F. A ambigüidade da docência entre o profissionalismo e a proletarização. Teoria e Educação. Porto Alegre, Pannonica, 1991, nº 4, p.41-61.

. Educar em tempos incertos. Porto Alegre, Artmed, 2004.

FREITAS, H. C. L. de. Formação de professores no Brasil: 10 anos de embates entre projetos de formação. Educação e Sociedade, Campinas, v.23, n 80, p.137-168, set. 2002.

A (nova) política de formação de professores: a prioridade postergada. Educação e Sociedade, Campinas, v. 28, Número Especial, p. 1.203-1.230, 2007.

GATTI. B. Diagnóstico, problematização e aspectos conceituais sobre formação do magistério: subsídio para delineamento de políticas na área. SP, FCC/DPE, 1996.

MAUÉS, O. C. Reformas internacionais da educação e formação de professores. Cadernos de Pesquisa. SP: Fundação Carlos Chagas, n 118. p. 89-117, mar. 2003.

BRASIL. Presidência da República. Lei no 9.394, de 20 de dezembro de 1996. Estabelece as Diretrizes e Bases da Educação Nacional. Brasília: Publicada no D.O.U. n 48, 23/12/96. 
BELÉM, Prefeitura Municipal de Belém. Lei Orgânica do Município de Belém. Aprovada de 30/03/1990. In: http:// www.belem.pa.gov.br/new/index.php Acesso em 10/11/2010.

Lei 7.502 de 20 de dezembro de 1990 - Dispõe sobre o Estatuto do Funcionário Público de Belém. CEJUP, 1993.

Lei n 7.507 de 14 de janeiro de 1991 - Dispõe sobre o Plano de Carreira do Quadro de Pessoal da Prefeitura Municipal de Belém. CEJUP, 1993

Lei $n^{\circ}$ 7.528, de 5 de agosto de 1991 - Dispõe sobre o Estatuto do Magistério Público de Belém. CEJUP, 1993.

Lei $n^{\circ} 7.638$ de 24 de maio de 1993 - Disciplina o desconto por motivo de falta de integrantes da Carreira do magistério. CEJUP, 1993.

Lei 7.673 de 21/12/1993 - Dispõe sobre o sistema de promoção do Grupo Magistério, modificada pela Lei $n^{\circ} 7.853$ de 24/11/1997. CEJUP, 1993.

Lei no 8.487 de 29/12/2005 - Dispõe sobre a concessão de incentivo ao aperfeiçoamento. CEJUP, 1993.

Lei no 7.722 de 07 de julho de 1990 - Dispõe sobre a criação do Sistema Municipal de Ensino. In: http://www.cmebelem.com.br/docs/lei772294.pdf Acesso em 01/12/2010.

JUNIOR, Adhemar F.D et all. Plano de Carreira e Remuneração do Magistério Público: LDB, FUNDEF, diretrizes nacionais e nova concepção de carreira. FUNDESCOLA, MEC, s/d.

LUZ, Sílvia Letícia D'Oliveira da. A valorização do profissional da educação e a carreira docente: a experiência do governo de frente popular em Belém do Pará, 2008. Dissertação (Mestrado em Educação) - UFPA, ICED, Programa de Pós-Graduação em Educação, Belém, 2008.

MONLEVADE, A. C de. Valorização Salarial dos Professores: o papel do piso salarial profissional nacional como instrumento de valorização dos professores da educação básica pública. Campinas, SP: [s.n.], 2000.

ROSÁRIO, M. J. A. do: SOUSA, M. de F; MELO, C. N. Guia de fontes sobre o ensino público de Belém do Pará, no Século XX: da instrução primária ao ensino fundamental. Belém-Pará. UFPA - ICED, 2008. In: http://www. histedbr.fae.unicamp.br/acer_histedbr/seminario/seminario8/_files/h4qNViFr.pdf. Acesso em 02/11/2010.

Sites Institucionais consultados:

http://www.belem.pa.gov.br/new/index.php

http://www.ibge.gov.br/cidadesat/topwindow.htm?1

http://www.belem.pa.gov.br/semaj/app/paginas/lom.html

http://www.sintepp.org.br/

http://www.inep.gov.br/ 